\title{
Ectopic Breast Tissue in the Vagina Detected at the Median Episiotomy Site
}

\author{
Kyoung-chul Chun ${ }^{\mathrm{a}}$, Myounghwan Kim ${ }^{\mathrm{b}, \mathrm{c}}$
}

\begin{abstract}
When regression of the milk line remnants fails during embryogenesis, ectopic breast tissues can arise at any point along the embryonic milk lines. However, ectopic breast tissues could also arise outside the milk lines. A 30-year-old pregnant woman delivered at 38 3/7weeks gestation by normal birth. In the inner side of the hymen at the median episiotomy site, a grayish-brown soft tissue was noted. A clinical provisional diagnosis of inclusion cyst was made. Postoperative histology showed the pathological features of a breast tissue. Excision is recommended for confirming this pathology and treatment. Despite its rarity, ectopic breast tissue should be considered in the differential diagnosis. This is the first case, to our knowledge, of vaginal ectopic breast tissue in a parturient woman.
\end{abstract}

Keywords: Ectopic breast tissue; Episiotomy; Inclusion cyst; Vagina

\section{Introduction}

Ectopic breast tissues may arise at any point along the embryonic milk lines, which extend bilaterally from the axilla to the medial aspect of the upper thigh [1]. The milk lines normally disappear, except in the thoracic region where the normal breast tissue develops. However, when regression of the milk line remnants fails during embryogenesis, the breast tissue develops in the ectopic area. Ectopic breast tissues can also arise outside the milk lines. Ectopic breast tissues have been reported in the axillae and vulva and less commonly in the buttock, neck, face, flank, arms, hips, shoulders, and back [2, 3].

Van der Putte proposed the normal existence of mammarylike anogenital glands and dismissed the traditional theory of ectopic breast tissue [4]. However, this theory seemed not to be

Manuscript submitted June 6, 2018, accepted June 22, 2018

aDepartment of Obstetrics and Gynecology, Ilsan Paik Hospital, Inje University, School of Medicine, Goyang, Korea

bepartment of Obstetrics and Gynecology, Sanggye Paik Hospital, Inje University, School of Medicine, Seoul, Korea

${ }^{\mathrm{c} C}$ Corresponding Author: Myounghwan Kim, Sanggye Paik Hospital, Inje University, 1342, Dongil-ro, Nowon-gu, Seoul, 01757, Korea.

Email: myankim@paik.ac.kr universally accepted, with some authors suggesting the presence of both mammary-like glands and ectopic breast tissues in the anogenital region [5]. Atwal et al recently demonstrated a vulval fibroadenoma with adjacent supernumerary breast tissues [5]. This finding added further evidence to the existence of ectopic breast tissues in the anogenital region, perhaps in combination with anogenital mammary-like glands.

Here, we describe a case of a vaginal ectopic breast tissue found after normal vaginal delivery. To the best of our knowledge, this is the first reported case of vaginal ectopic breast tissues.

\section{Case Report}

A 30-year-old pregnant woman, gravida 1, para 0, at 37 weeks gestation was referred to our hospital for a Cesarean section because she had a history of laparoscopic right ovarian cystectomy and myomectomy at Sanggye Paik Hospital in Seoul, Korea the previous year. Her operation record showed that she had subserosal myomectomy and ultrasound examination revealed a vertex presentation and placental location at the anterior wall of uterus. Given that the risk of uterine rupture is low in patients who have undergone subserosal myomectomy, we decided to attempt a vaginal delivery. Moreover, she complained that she had recently started experiencing pain in the posterior vaginal wall.

At 38 weeks and 3 days of gestation, she was sent to the delivery room due to complaints of regular abdominal pains and watery vaginal discharge. Labor augmentation was performed with oxytocin, and the patient delivered a healthy male infant, who weighed 3,235 g, by vaginal delivery. In the inner side of the hymen at the median episiotomy site, approximately $2 \mathrm{~cm}$ of grayish-brown soft tissue was noted. A clinical provisional diagnosis of inclusion cyst was made. Excision of the cyst was performed. Postoperative histology showed simple or complex glands lined by luminal columnar epithelium surrounded by myoepithelial cells in fibrocellular stroma (Fig. 1A). Immunohistochemical testing result was positive for CK5, CK6, p63, pancytokeratin, CD10, and progesterone receptor (Fig. 1B-D) but negative for CD34 and estrogen receptor. The pathological features were those of breast tissues.

\section{Discussion}

The primitive embryological milk line appears in the fifth week 

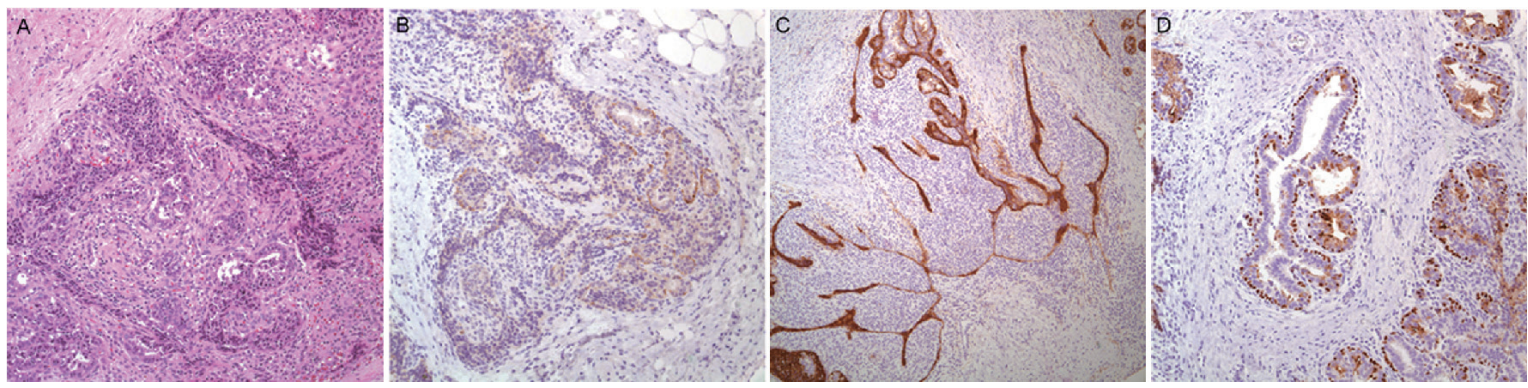

Figure 1. Histologic findings of anogenital mammary-like glands. (A) Simple or complex glands lined by luminal columnar epithelium surrounded by myoepithelial cells in fibrocellular stroma $(H \& E, \times 100)$. Focal expression of CK5 (B) in both luminal and myoepithelial cells is found. CD10 (C) and p63 (D) immunostaining was positive in myoepithelial cells.

of gestation when the embryo is $7 \mathrm{~mm}$ in length and extends from the axilla to the medial aspect of the groin. Soon thereafter, the milk line involutes, except in the mid-thoracic region where it forms band-like epidermal thickening and develops as a mammary ridge and then into the breast. Incomplete involution of the mammary streak gives rise to ectopic mammary tissues along the embryonic milk line. Mammary glands are modified sweat glands that develop from the mammary ridges, which extend from the axilla to the groin [6]. Accessory mammary glands occur more frequently in women than in men, and are generally sporadic, although familial forms have also been reported [7]. The traditional theory of ectopic breast does not support the presence of the vulvar and perineal ectopic breast tumors as seen in this case. Van der Putte suggested that specialized glands identical to the mammary glands normally exist in the anogenital area and have a close relationship with the eccrine glands. These glands are called mammary-like anogenital glands which are present in the anogenital region and are thought to be adnexal glands similar to mammary glands. Van der Putte's theory also states that the formation of these lesions does not require the existence of normal breast tissues $[4,8,9]$.

In 2006, Atwal published a case of previously documented supernumerary mammary tissue-originating vulvar fibroadenoma, describing a lesion that histopathologically mimicked a fibroadenoma with positive estrogenic receptors on immunohistochemistry and with healthy mammary tissues surrounding the lesion [5]. The presence of ectopic mammary tissue that is characteristically normal and surrounds a lesion, described as fibroadenoma, supports the theory of ectopic mammary tissue and shows that not all fibroadenomas are derived from anogenital glands similar to the breast, as van der Putte confirmed [4, 10]. Currently, a distinction is made between ectopic breast tissues and mammary-like anogenital glands, which are located at a more medial site proximal to the labia minora. These structures are simpler and present in greater numbers [4]. However, differentiation between the two entities is very difficult due to their remarkable similarities [7]. The immunohistochemical profile of mammary-like anogenital glands is also very similar to that seen in normal breast tissues [11]. Given that the tissue, in our case, was found at the posterior vaginal mucosa, just inside the hymenal ring, it more likely originated from mammary-like anogenital glands.

Ectopic breast tissues are subject to hormonal response and undergo physiologic changes, such as enlargement and milk secretion, during pregnancy. In addition, these tissues may develop various pathological changes, such as fibroadenoma, fibrocystic changes, sarcomatous changes, and carcinoma. However, carcinoma secondary to accessory breast tissue is rare, accounting for approximately $0.3 \%$ of all breast carcinomas [12]. There is no evidence that these changes are more frequent in accessory breasts [13]. For vulvovaginal lesions, differential diagnosis includes carcinoma, Bartholin gland disorders, epidermal inclusion cyst, and crural hernia. Excision is recommended for the pathologic confirmation and treatment of vulvovaginal lesions as well as of other lesions in ectopic breast tissues; however, liposuction has also been used [14]. Needle biopsy can be considered for histologic confirmation before excision.

We report the first case of a vaginal ectopic breast tissue in a parturient woman. Differential diagnosis of vaginal lesions should include this entity, especially given that it changes its size cyclically with menstruation and during pregnancy and lactation. The lesion itself should be excised, as this is a general consensus for vulvar and other ectopic breast tissues. No guidelines exist regarding follow-up in these patients in terms of whether to screen for ectopic breast malignancy or recurrence of ectopic tissue. Although the incidence of malignancy or recurrence is quite rare, ectopic breast tissues should also be considered in the differential diagnosis, especially during delivery.

\section{Conflict of Interest}

None.

\section{References}

1. Pathak S, Preston J. A rare case of multiple accessory breast tissue in the axillae, lower abdomen and vulval areas. J Obstet Gynaecol. 2007;27(5):531-533.

2. Grossl NA. Supernumerary breast tissue: historical perspectives and clinical features. South Med J. 2000;93(1):29-32.

3. Chung-Park M, Zheng Liu C, Giampoli EJ, Emery JD, Shalodi A. Mucinous adenocarcinoma of ectopic breast tissue of the vulva. Arch Pathol Lab Med. 
2002;126(10):1216-1218.

4. van der Putte SC. Anogenital "sweat" glands. Histology and pathology of a gland that may mimic mammary glands. Am J Dermatopathol. 1991;13(6):557-567.

5. Atwal GS, O'Connor SR, Clamp M, Elston CW. Fibroadenoma occurring in supernumerary breast tissue. Histopathology. 2007;50(4):513-514.

6. Moore KL, Persaud TVN. The integumentary system. In: Moore KL, Persaud TVN, editors. The developing human: clinically oriented embryology. Philadelphia, PA: W.B. Saunders Co; 1998, p. 513-530.

7. Hong JH, Oh MJ, Hur JY, Lee JK. Accessory breast tissue presenting as a vulvar mass in an adolescent girl. Arch Gynecol Obstet. 2009;280(2):317-320.

8. Cantu de Leon D, Perez Montiel D, Vazquez H, Hernandez C, Cetina L, Lucio MH. Vulvar fibroadenoma: a common neoplasm in an uncommon site. World J Surg Oncol. 2009;7:70.

9. Anunobi CC, Obiajulu FJ, Banjo AA, Okonkwo AO.
Vulva fibroadenoma associated with lactating adenoma in a 26-year-old nigerian female. Case Rep Pathol. 2013;2013:195703.

10. van der Putte SC. Papillary "apocrine" fibroadenoma of the vulva. J Cutan Pathol. 1998;25(2):126-127.

11. Konstantinova AM, Stewart CJR, Kyrpychova L, Belousova IE, Michal M, Kazakov DV. An immunohistochemical study of anogenital mammary-like glands. Am J Dermatopathol. 2017;39(8):599-605.

12. Rho JY, Juhng SK, Yoon KJ. Carcinoma originating from aberrant breast tissue of the right upper anterior chest wall : a case report. J Korean Med Sci. 2001;16(4):519-521.

13. Godoy-Gijon E, Yuste-Chaves M, Santos-Briz A, Esteban-Velasco C, de Unamuno-Perez P. [Accessory breast on the vulva]. Actas Dermosifiliogr. 2012;103(3):229232.

14. Aydogan F, Baghaki S, Celik V, Kocael A, Gokcal F, Cetinkale O, Unal H. Surgical treatment of axillary accessory breasts. Am Surg. 2010;76(3):270-272. 